\title{
LIFE CYCLE MODELS OF BUILDINGS - A NEW APPROACH
}

\author{
NIKLAUS KOHLER, BERTRAM BARTH, SANDRO HEITZ, \\ MANFRED HERMANN \\ ifib- Institut für Industrielle Bauproduktion. \\ Universität Karlsruhe, D-76128 Karlsruhe
}

Keywords:

Life cycle costs, Life cycle impact assessment, Product models.

\section{Life cycle costs}

The idea of life cycle cost was developed a quarter of a century ago. A wide dissemination of the term was given through a report for the US Secretary of Defense "Life Cycle Cost in Equipment Procuration" [LMI65]. This report was followed by a series of guide lines in the defense field and later on in other government activities. The basic definition of life cycle costs is: "The sum of all costs incurred during the lifetime of an item, i.e. the total of procurement and ownership costs." [DHI89]. The primary uses of life cycle costs are:

- comparing competing projects

- long range planning and budgeting

- selecting among competing bidders

- controlling an ongoing project

- comparing logistic concepts

- deciding on the replacement of an aging equipment.

There are several life cycle costs models available in literature. [DHI89] distinguishes between general, non specific models and specific models developed for a particular application.

In the building field attempts have been made to introduce the notion of life cycle costs mainly through building surveys and for public owned buildings [TRE75], [BEK80].

Recorded data of construction, refurbishment and maintenance costs of buildings show that over a 50 year period the total costs amount to approximate twice the investment costs (without financial costs). 


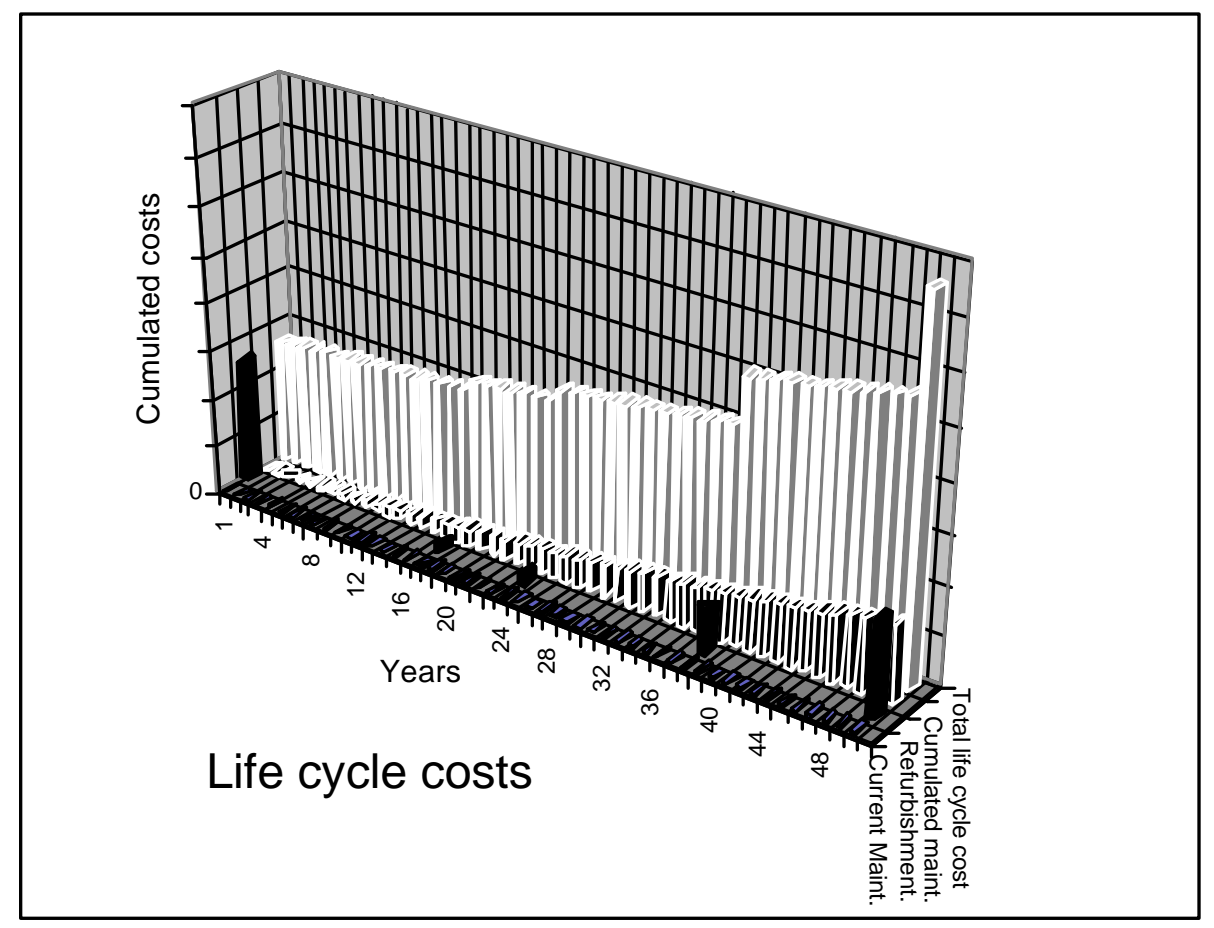

Figure 1. Total costs of a swiss appartement building over 50 years [BFK93]

All existing life cycle cost models reflect the objectives of the equipment's owner. Even if they take into account all costs occuring during the life cycle, they generally only consider "real costs", which have to be paid. The environmental issue leads automatically to an extension of this traditional life cycle costing. The real overall cost of any type of item is much larger than the costs actually paid (including interests) if we take into account the social costs associated with production, use and disposal. For objects with large resource consumption (energy, land, mass) and emissions, this aspect becomes predominant. These costs are considered "external" costs in economic theory [KAP51],[HOH88], because they are not charged to the user of a piece of equipment but are accounted for by society (this is why they are also called "social" costs). The idea of adding at least the energy and direct emissions (pollution) aspects to general life cycle costs in the building field is quite recent [KOH87].

The calculation of life cycle costs as well as mass flows has to take into account the specificity of buildings compared to current industrial products. First of all buildings are very complex products. This complexity is hidden by the fact that we all live in buildings and consider them to be simple and obvious things. But the planning process is long and complicated, because a great number of technical, social, economical, ecological and cultural factors have to be considered. Buildings have a life time, which is much longer than current industrial products and the conditions of use change frequently and are difficult to predict. Through their long life time and their link to the 
site, buildings have been one-of-a-kind products. Even if techniques of industrial mass production have been introduced to parts of buildings, the one-of-a-kind nature of the whole object remains. However planning will be considerably improved by new computer based techniques.

Concerning the global environmental impact, the building stock induces the largest energy and mass flows of all production sectors. It represents the largest financial, physical and cultural capital of the industrialized societies. In the future it will also become the largest raw material resource for new buildings.

Taking these facts into account, the classical life cycle costing approach must be considerably enlarged in two directions:

Time system limits: A building starts with the expression of a social need and it ends with the physical disposal of the construction materials.

Domain system limits: A building creates, during its whole life time, an ongoing extraction of materials and energy from nature and a large and ongoing flow of emissions back into nature. The ecosphere becomes the final system limit.

\section{Life cycle based criteria}

\subsection{SYSTEM LIMITS}

The basic modeling approach for the life cycle of buildings does not start from geometry but from system theory and in particular from ecological system theory. For Odum "the environment has organisms, chemical cycles, water, air, humans, machines, soil, cities, forests, lakes, streams, estuaries, and oceans; and connecting them all are flows of energy, including that associated with matter and information" [ODUH83]. The environment can be described in a system language, which is basically an energy circuit language. In this system all occuring phenomena are accompanied by energy transformations. The energy language keeps track of flows of potential energy from sources going into storages or into transformation (work) and finally into degraded forms leaving the system as heat sinks. Pathways of the energy language are pathways of energy flow.

The rate of flow of energy into useful work is defined as power.

In this processes the first (conservation) and the second (entropy) laws of thermodynamics apply. Odum adds a third important principle, which has been observed in natural systems: the feedback of energy from storage stimulates the inflow pathways as a reward from receiver storage to inflow source. By this feature the flow values developed reinforce the processes that are doing useful work. Feedback allows the circuit to learn. Lotka formulated the maximum power principle, suggesting that systems, which develop designs that maximize the flow of useful energy prevail. 


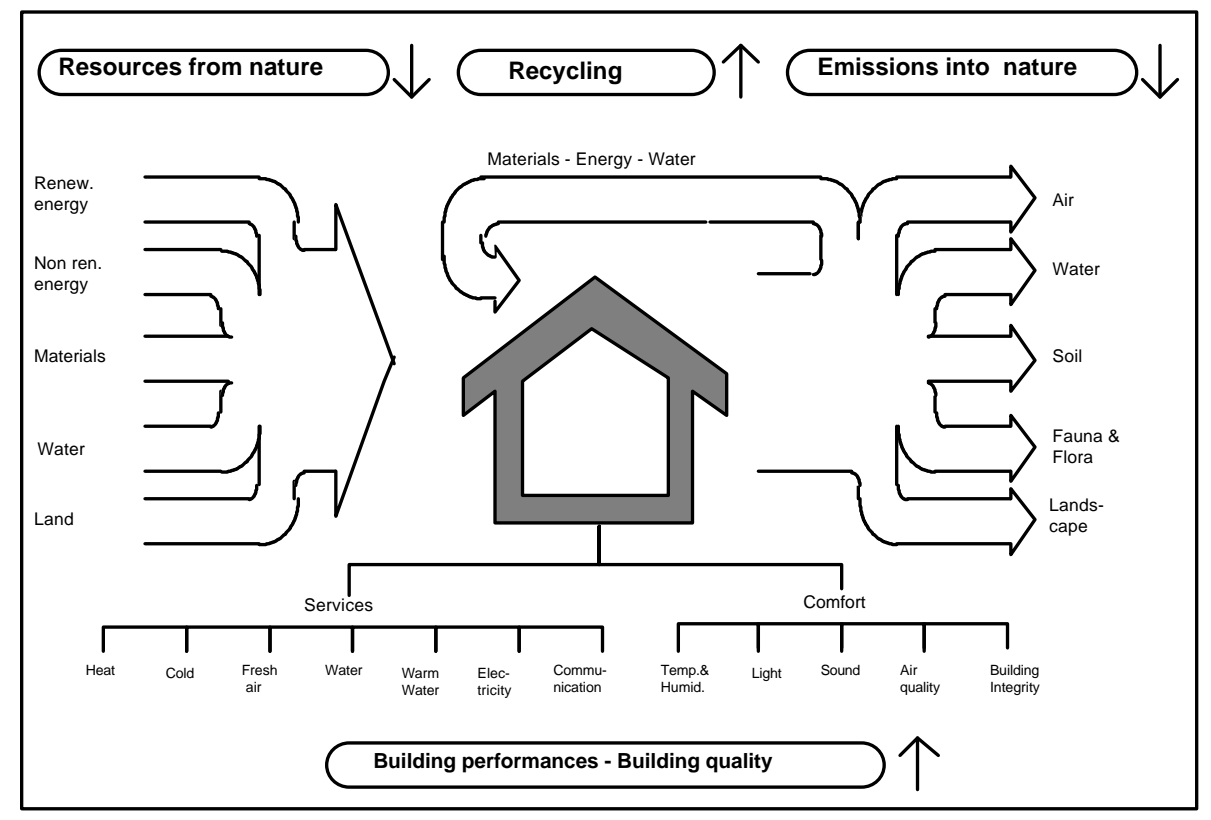

Figure 2. Resource and emission flows of a building [REG96]

The concept of system limits refers basically to the limits in time and space. This approach has been developed in a qualitative [ODUE71,ODUH83] and quantitative [LOT25] way by system ecology [DEL92] and has become the basis of life cycle impact assessment (LCIA). The experience from life cycle impact assessment shows that all results depend strongly on the chosen system limits. This is particularly true for the economic and ecological aspects of the building process.

\subsection{ENERGY AND MASSFLOWS}

A building can be represented during its life time as the superposition of different flows and activities along the different phases of its life time:

Physical flows:

- Material (building material, water).

- Energy (embodied and operation energy).

- Waste (building materials and waste from use).

- Emission (waste released into the air or soil).

Financial flows:

- Internal costs

- External costs

Information flows:

- Documents

- Communication in all forms 
Money is an exchange medium that flows as a countercurrent to materials, energy and information flows. Financial flows can therefore be associated with all of the physical flows and activities. This allows to identify the internal as well as the external costs. All planning and managing activities include documentation and communication as well as data processing in many forms. These are all information flows.

In order to be able to establish the life cycle costs, the flows of materials and the construction operations of a building must be known for its entire life cycle. This knowledge exists to a large extent today, but it is dispersed and in very different formats. All building operations (planning as well as construction and use) can be evaluated according to mass flow, energy flow, information flow, resource use, financial flows and environmental impact criteria. The techniques of life cycle impact assessment (LCIA) [SET91,93] show that it is very important to separate the quantitative data from the evaluation. The evaluation of the flows from different points of view and their assessment in a larger context must always be possible. The goal of the evaluation is to enable the decision maker (designer, owner, politician, producer) to make conceptual, political, constructive and economic choices.

\subsection{FUNCTIONAL UNITS}

The notion of functional (or reference) unit is used in LCIA as well as in the traditional cost planning techniques like cost targeting. The performance based approach in planning is entirely dependent on a coherent choice of functional units. By taking into account several life cycle phases, the choice of common functional units becomes decisive for the possibility to practice feedbacks and learn from past experience.

\subsection{TIME CONSTANTS}

Buildings can be considered as composed of elements and parts with very different time constants varying from nanoseconds for light propagation to hundreds of years for the replacement of bearing structures.

\begin{tabular}{|ll|}
\hline Nanosecond & Light \\
Second & Sound \\
Minute & Air movement \\
Hour & Temperature \\
Day & Energy \\
Week & Use cycle \\
Month & Cleaning \\
Year & Maintenance \\
10 Years & Refurbishment \\
100 Years & Life time \\
\hline
\end{tabular}

Figure 3. Time constants in buildings 
Furthermore several time scales are superposed: planning time, use time, building life time; they all have historical character and are not reversible. Furthermore according to the second principle of thermodynamics buildings always contribute to the raise of entropy, only the speed of the process can be influenced by planning and use techniques.

\subsection{PROCESSES}

The life cycle approach leads to a dynamic way of understanding buildings. This is opposed to the predominantly static way of describing buildings, essentially by preferring the geometric, static way of actual CAD systems' descriptions. At present there is a shift from the geometric modeling based CAD approach to a work flow based modeling approach. Because of their work flow character it is difficult to integrate cost planning, scheduling, specification, refurbishment and facility management into the exsting CAD systems. By analyzing the work flow process we realize that they finally all relate to energy and mass flows from and to nature. These flows will therefore become the fundamental process unit in the description of the building process during its life time.

The recent attempts to apply ecological models to computing [HUB88] offer new perspectives for more complex conceptual modelization and scientific computing (simulation, computer experiments). New modeling and computation techniques allow to simulate decentralized, distributed systems supporting complex simulation as well as new cooperative planning techniques through the use of networks.

\section{Process modelization}

\subsection{PRESENT BUILDING MODELING}

The need to explicit modeling of buildings emerges from the recognition of the limits of existing geometry based CAD systems [IWC89]. There has been an agreement that only a common semantic model could be a basis for different applications and views. The ongoing modeling discussion is generally agreeing on a distinction between rooms (functions) and building elements (construction elements and systems). For certain applications like cost planning a hierarchical approach is appropriate [BED92], for other aspects like topology, other models are necessary. There is still a large discussion about the way to introduce object oriented techniques on a modeling and software engineering level. First attempts to use agent based techniques are recorded. The STEP approach integrated the life cycle perspective from the beginning [GIE88]. The present discussion around the building application protocol of STEP is still not finished, no clear standard solution is in sight. 


\subsection{DESIGN AND BEHAVIOR}

The modeling of the design process has as a target the object, which has to be constructed. In this stage the object has no existence and therefore no behavior yet. The dynamic aspects related to the building process and building use are not modeled in detail. If we look at buildings during their life cycle, we look mainly at existing buildings, at the building stock. The diagnosis of the temporal behavior of existing buildings becomes the main interest in modeling, the center of the models. New construction becomes a special case of maintaining buildings [KOH94].

\subsection{THE PERFORMANCE BASED APPROACH}

The idea of a performance based approach in building comes from the attempts to develop open industrialized building systems. The implementation of solar energy related research and energy conservation strategies could not succeed as long as there were no clear performance standards for all phases of the design, planning and use process. Cost planning techniques, above all cost targeting, also used performance approaches. The application of life cycle impact analysis has given an additional importance to the performance aspect by introducing a whole series of new targets and functional units. In all cases the determination of the reference unit is very important. By analyzing the performance standards, above all in life cycle impact assessment the questions became more and more fundamental. Taking into account the new system limits and the considerable mass and energy flows induced by the very first decision to build, the new question was: do we really need a building, or can we solve the same problem by other means, which have less impact? Often non-building solutions (e.g. through the application of information and communication techniques) prove to be preferable to a building.

\section{The common building model}

\subsection{THE "BUILDING AS BUILT"}

The basic idea is that the common model for the life cycle of building can only be the "building as built". Several authors came to the same conclusion [BJÖR92]. The "building as built" is the starting point of the life time of a building and of its induced mass, energy, work and monetary flows. All planning steps, which precede the "building as built" can be considered as a temporarily uncompleted building or as not yet instantiated structure. 


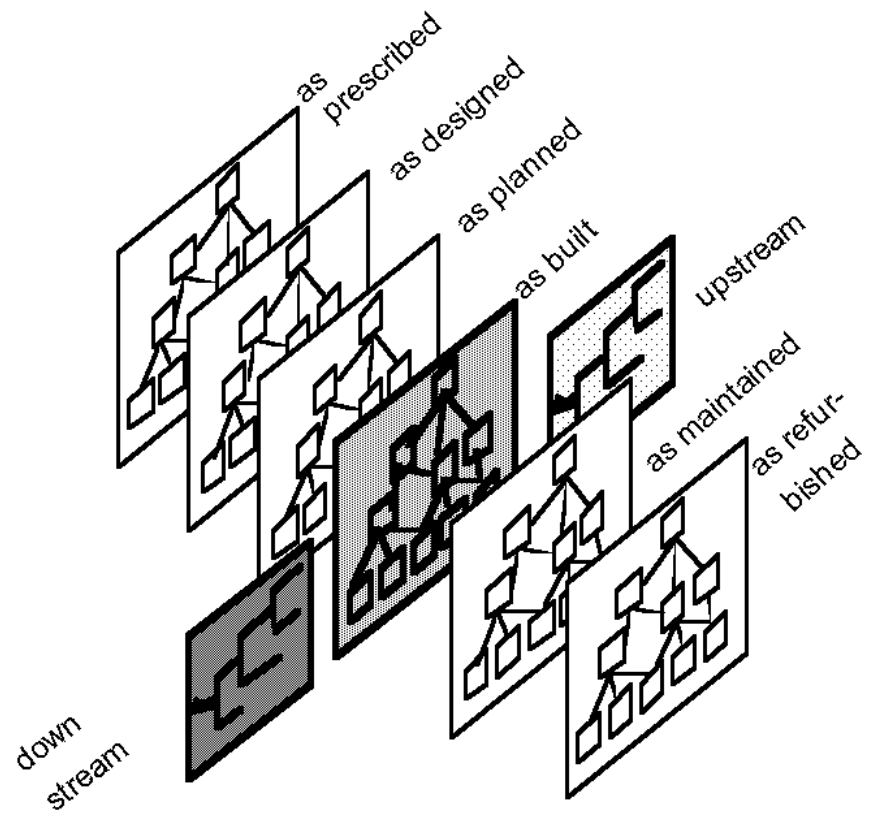

Figure 4. Overview of the life cycle model

The design process reveals the building (it discovers the underlying structure). The questions of functional units is very crucial because as long as a functional unit has not been given a specific value through a planning decision, it must take a default value, which can be the average value of a large number of similar buildings. This allows to produce a large number of simulations of possible design outcomes, which are of course not exact, but which are plausible.

The basic assumption is that buildings of a certain function (housing, office buildings, hospitals, factory etc.) are much more similar than we generally think. Their cost and environmental impacts during their life time can already be determined during the design brief and through performance specification by associating performances and functional units. It also implies that simulation techniques can be used very extensively to verify if the performance targets are reached during the ongoing planning phase.

The impacts of the building during the life cycle phases after construction (building as maintained, refurbished and demolished) can be simulated the same way, taking into account the upstream and the downstream processes.

The question of how to integrate time into the life cycle models is crucial. As well as there are different time constants in the building construction and use, there are 
different uses of time during the planning process and the life time of a building. It is important that they all refer to a common scale. This is fundamental for several planning problems:

- the management of planning time, above all the versioning problem

- the management of construction time (scheduling)

- all simulation referring to energy, environment, construction

- facility management

- replacement strategies

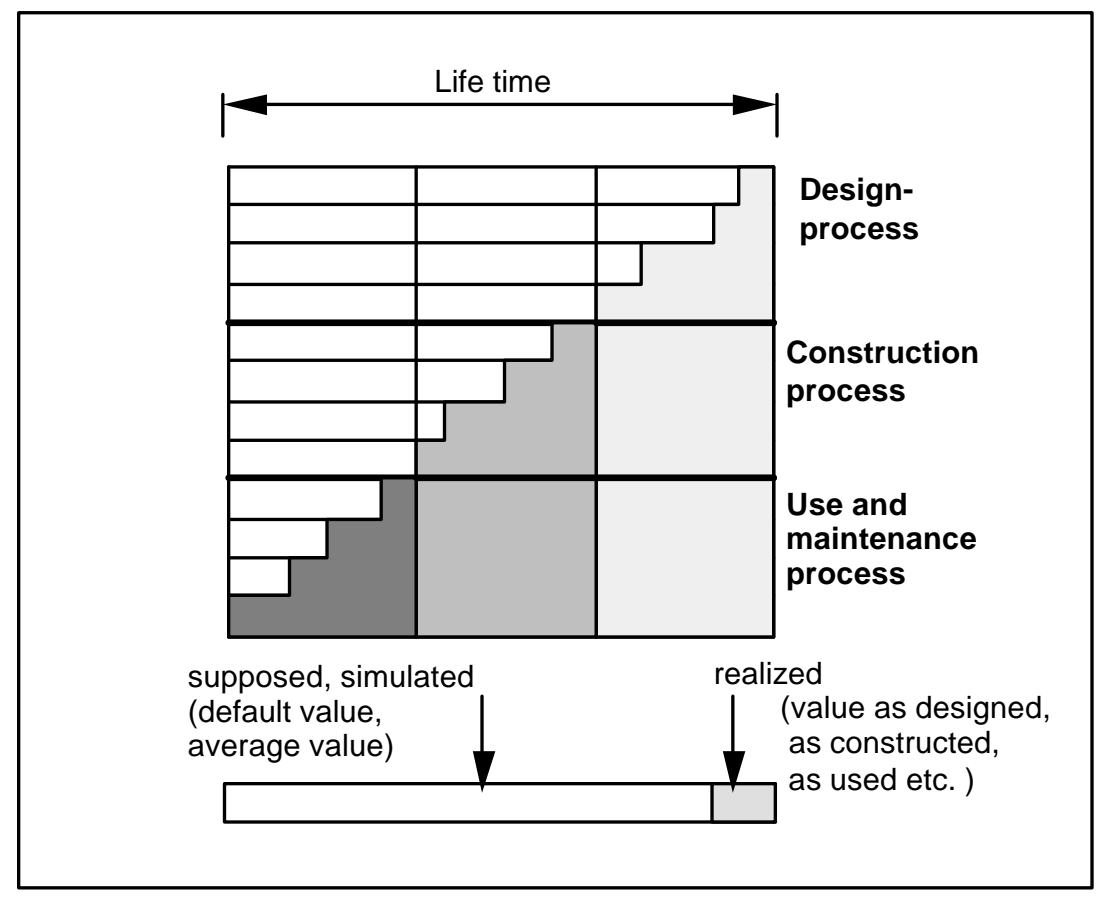

Figure 5. The planning process as combination of realized and supposed parts

\subsection{THE PLANNING PROCESS}

If we consider the "building as built" as the central representation then the planning and use process of a building can be considered as the gradual replacement of average or default values by actually realized values. In the beginning a building is therefore described by $99 \%$ of average (default) values and $1 \%$ really planned (realized) values. This principle can be applied through the use of different (common) functional units. The advantage is that the whole building is considered and nothing is forgotten. It is therefore possible to represent buildings as combinations of planned and not 
planned parts, of realized and supposed parts, of real and virtual parts, of past, present and future parts. 


\section{Implementation}

\subsection{CATALOGUES AND STRUCTURES}

A large part of information and knowledge about buildings is contained in catalogues. Catalogues of building systems (they can vary from small parts of buildings to whole buildings) establish relations (rules) between the different parts, defining in this way a coherent solution. The whole building can therefore be considered as situated in an ndimensional space containing all the possible solutions. The same approach can be made with specifications and their aggregation into construction elements [HEI95]. There is a considerable knowledge available in this form, which has not been taken into account because it did not "fit" to the present building models and CAD systems. Standards and professional rules contain very complicated structures (element decomposition for cost planning, energy calculation, contractual schemes, procurement methods, specification of planning tasks, classification of documents etc.). They actually structure the planning process at present time, but they are not integrated.

\subsection{COOPERATION AND COMMUNICATION MODELS}

The cooperation mechanisms in a one-of-a-kind production are complex, to control them is essential. The planning process being mainly performance driven, the issue of reference units as nodes in the horizontal integration (cooperation between planners) as well as the vertical integration (simulation and feedback over the phases of the planning process) are of great importance. The reference units can also be situated in time giving this network a strongly structuring aspect of the whole planning process. However, the comprehensive modelization of cooperation is difficult, a first attempt is the modelization of communication, above all in written form (document management), which could be enlarged with the mentioned network.

\subsection{BUILDING REPRESENTATION}

A building in general can be most easily described as composed of:

- a particular building, which has functions, is situated on a particular site and has a time of existence. It is composed of

- $\underline{\text { rooms, }}$ which have functions and requirements. Their reference units refer to functions (e.g. $1 \mathrm{~m}^{2}$ of classroom of an elementary school) and requirements (e.g. light level, resulting temperature). All information related to rooms is contained in the so called room book, which evolves during the life cycle of the building. Rooms are delimited by construction elements and contain system elements

- elements, which have a physical reality and performances. They are either construction elements (separation and structure functions) or system elements (technical functions, converting or transporting different media). In addition to their compositional information they have other characteristics like their status 
(degree of realization: average, planned, new, refurbished etc.), their time tag and their data status (form of description, origin, quality, contract status). Their reference units refer to their composition (material layers, duct characteristics), performance (e.g. acoustic absorption, efficiencies) and use of resources (cost, materials, land, time).

- use processes of rooms, which are dynamic (evolution of temperature during a day, change of function after 10 years).Their reference units relate to the requirements (e.g. internal loads in $\mathrm{W} / \mathrm{m}^{2}$ ). They consume resources and create emissions.

- construction and maintenance processes, which are dynamic and which refer to elements (set up time, probable life span). Their reference units are those of the specifications. They consume resources and create emissions.

- resources of different types. Their reference units are related to mass, energy and time flows.

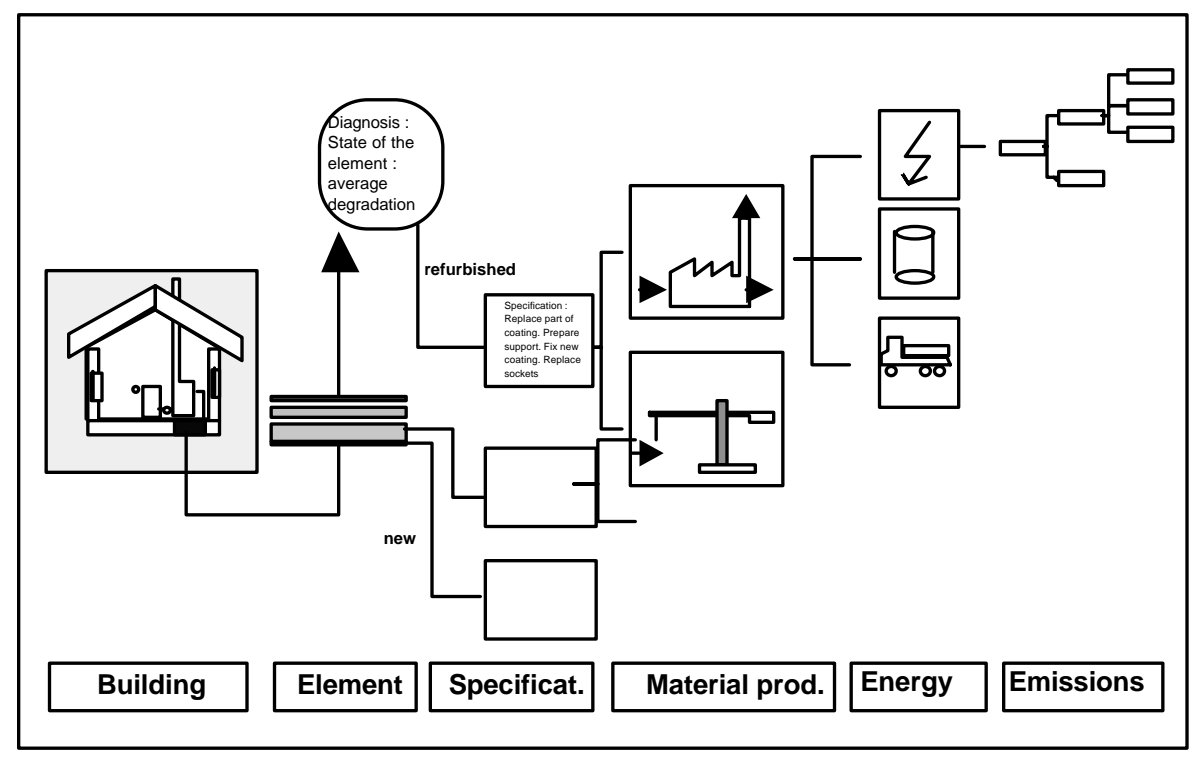

Figure 6. Building representation based on elements and specifications

There are complex topological relations between rooms and elements. Rooms are defined by surfaces of construction elements and contain technical system elements. Technical systems have their own compositional structure (generally hierarchical). The reference units are interrelated through the composition of the building. They can generally be recomposed by generalization from the "building as built" to earlier stages. In the other direction this is not possible without additional information. The "building as built" can be considered as the most complete representation of a building. All other stages can be derived (by generalization for the early design 
phases, by simulation of the use and deterioration for the life cycle). The largest part of the information about a "building as built" is contained in the complete specifications.

There are catalogues of specifications and catalogues of elements composed of specifications, which allow to describe most buildings. At present time, the most complete general description of a building is given by the structure and standard specifications, which are used in cost estimation [CRB91].

\section{Conclusions}

The life cycle approach is not an additional view to the actual, mainly design and geometry based representation of a building. It is a different structural principle, which has the following characteristics:

- it has large and explicit system limits

- it is process based and not object or geometry based

- it uses reference (functional) units to link construction and performance

- the central modeling level is the "building as built"

- it integrates different time levels

- it allows to combine real and virtual components

- it integrates existing construction, cost, energy and mass flow data

- it is based on existing data contained in catalogues etc. 


\section{References:}

[BED92] Bedell, J.R., and Kohler, N. (1992): "A Hierarchical Model for Life Cycle Costs of Buildings", Proceedings of the Computers in Building W78 Workshop, May 1992.

[BEK80] Bekker, P.C.F. (1980): "Life time theory of dwellings", in CIB Symposium Quality and Cost, in Building. EPFL Lausanne 1980

[BJÖR92] Björk, B.-C. (1992): " A Unified Approach for Modelling Construction Information”, Building and Environment, special issue on databases for project integration, 1992.

[CRB91] CRB (1991): "CCE Cost Classification by Elements", CRB Swiss Research Centre for

Rationalization in Building and Civil Engineering, Zurich 1991.

[DEL92] Deléage, J.-P. (1992): "Histoire de l'Ecologie", Paris 1992

[DHI89] Dhillon, B.S. (1989): "Life cycle costing", New York 1989

[GIE88] Giehling,W.F. (1988): " General reference model (GARM) ”, TNO Report BI-88-150, 1988

[HEI95] Barth, B.; Eiermann, O.; Haida, A.; Heitz, S.; Hermann, M.; Kukul, E.: " Life cycle modeling of

buildings", in EuropIA'95, Lyon 1995, Hermes, Paris 1995

[HOH88] Hohmeyer (1988): "Social costs of energy consumption", Berlin 1988

[HUB88] Hubermann, I.A.: " The ecology of computation", Elsevier, Amsterdam. 1988. computing

[IWC89] International Workshop on Computer Building Representation, CH-Chexbres 1989, EPFL-

Lausanne 1989

[KAP51] Kapp, W. (1951): "The social costs of private entreprise”, Harvard 1951

[KOH87] Kohler, N. (1987): "Energy Consumption and Pollution of Building construction", International

Congress on Building Energy Management 87, EPFL Lausanne 1987

[KOH91] Kohler, N. (1991): "Life cycle costs of buildings", Buildings and the Environment, Proceedings of

the Forum at the University of British Columbia, Vancouver BC, March 1991

[KOH94] Kohler, N. et al.: "Energie- und Stoffflußbilanzen von Gebäuden während ihrer Lebensdauer", Schlussbericht Forschungsprojekt BEW, Ifib - Universität Karlsruhe 1994

[LMI65] Logistic Management Institute (1965): "Life cycle costing in equipment procurement", Washington D.C. 1965

[LOT25] Lotka, A.J. (1925): "Elements of mathematical biology", New York 1925

[ODUE71] Odum, E.P. (1971): "Fundamentals of Ecology", Philadelphia 1971

[ODUH71] Odum, H.T.: "Environment, power and society", New York 1971

[ODUH83] Odum, H.T. (1983): "System Ecology", New York 1983

[ODUH87] Odum H.T.; Pillet G.: "Energie, écologie, environnement", Geneva 1987

[ROE71] Georgescu Roegen N. (1971): ” The entropy law and the ecomomic process", Cambridge Mass.

1971

[SET91] SETAC (1991): ” A Technical Framework for Life Cycle Assessment",

Smugglers Notch Workshop Report, Washington D.C., USA 1991, 134p.

[SET93] SETAC (1993): " A conceptual framework for Life-Cycle Impact

Assessment", mars 1993, 146 p.

[TRE75] Trenton, H.P. (1975): ” Terotechnolgy: the right lifespan”, Building, April 1975, London

[BFK93] Impulsprogramm Bauliche Erneuerung: "Unterhaltskosten von Gebäuden und Bauteilen”,

Bundesamt für Konjunkturfragen, Bern 1993

[REG96] Final report REGENER Project, Ecole des Mines, Paris 1996 